\title{
Welding induced residual stresses in explosion cladded AL-6XN superaustenitc stainless steel and ASME SA516-70 steel composite plates
}

\author{
Rogério Varavallo, a, Vitor de Melo Moreira, ${ }^{1, b}$, Vinicius Paes ${ }^{1, c}$, Pedro Brito ${ }^{2, d}$, \\ Jose Olivas $^{3, e}$ and Haroldo Cavalcanti Pinto ${ }^{\star 1, f}$ \\ ${ }^{1}$ Universidade de São Paulo, Av. Trabalhador São Carlense 400, 13566-590 São Carlos SP, \\ Brazil. \\ ${ }^{2}$ Pontifícia Universidade Católica de Minas Gerais, Av. Dom José Gaspar 500, 30535-901 Belo \\ Horizonte MG, Brazil. \\ ${ }^{3}$ Dynamic Materials Corporation, 5405 Spine Road, Boulder, CO 80301, United States. \\ aroger_varavallo@yahoo.com.br, bvitor.s.melo@hotmail.com, ‘vinipaes@hotmail.com, \\ dpbrito@pucminas.br, eJOlivas@dynamicmaterials.com, fharoldo@sc.usp.br \\ ${ }^{*}$ Corresponding author.
}

Keywords: Explosion welding, superaustenitic stainless steel, heat treatment, residual stress.

\begin{abstract}
Explosion welding is a solid state joining process that allows the manufacturing of corrosion resistant structural composite materials in the form of plates. In the present work, composite bimetal plates of AL-6XN superaustenitic stainless steel and ASME SA516-70 carbon steel produced by explosion welded were studied. Post-weld annealing for stress relief was conducted at $600{ }^{\circ} \mathrm{C}$ for $30 \mathrm{~min}$ and the materials were examined in both the as welded and heat treated conditions. The microstructure of the weld was characterized by optical and scanning electron microscopy and the variation of hardness across the cladded interface was determined by applying Vickers microhardness. The residual stresses generated by the explosion welding process were analyzed by X-ray diffraction using the $\sin ^{2} \psi$ technique. The cladded interface exhibited a wavy morphology, characteristic of high bonding strength in explosion welds and the variation of hardness was found to be strongly influenced by strain hardening at the cladded interface. Elevated tensile stresses $(700 \pm 30 \mathrm{MPa})$ were present after explosion welding. Application of the proposed heat treatment allowed for significant stress relaxation, with a final tensile stress of $93 \pm 10 \mathrm{MPa}$.
\end{abstract}

\section{Introduction}

Explosion welding is a solid state welding technique employed for producing composite metal plates which relies upon the energy released by the detonation of an explosion to bring metal surfaces into intimate contact. The technique can be applied for joining large surfaces of dissimilar metals and the joints obtained by explosion welding are considered to have high mechanical strength, very narrow (if any) heat affected zones and, since bonding occurs in the solid state, some of the problems arising from fusion welding processes, such as formation of brittle intermetallics, are avoided [1]. In the usual configuration, the metal parts to be joined by explosion welding are normally called flyer and base plates. The materials are initially supported by a frame and kept separated by a predetermined standoff distance. An explosive is placed on top of the flyer plate which is accelerated towards the base plate after detonation. Upon impact, the colliding surfaces become plastic which promotes hydrodynamic flow of the metals in the form of a high velocity jet that sweeps impurities away from the interface, thus assisting the establishment of a strong metallurgical bond [1-4].

The performance of cladded plates (as other welds) can be influenced by residual stresses formed during the welding process, which may cause e.g. dimensional instability during cutting or machining operations. In general, residual stresses arise in welding processes due to inhomogeneous 
temperature distributions. At the bonding interface, temperatures are significantly higher than in the base materials. This is true also for explosion welding process, due to partial conversion of the elevated impact energy to heat which may indeed produce local melting and/or annealing in the vicinities of the interface [5]. Thus, upon cooling, the regions near the cladded interface tend to contract while hindered by the surrounding base material. This may lead to elevated tensile stresses close to the welding interface with balancing compressive stresses throughout the parent metals [6]. In the case of dissimilar materials, residual stresses are further enhanced by differences in elastic properties and Coefficient of Thermal Expansion (CTE) among the base materials [7]. This has led to a number of recent investigations with the objective of determining residual stresses in clad plates produced by explosion welding [8-12] and studying stress relief treatments [13-15]

In the present contribution, an investigation of the microstructure and residual stresses formed as a consequence of the explosion welding process applied for the production of ASME SA516-70 steel and AL-6XN (UNS N08367) steel bimetal plates is proposed. The ASME SA516-70 steel is a carbon steel intended primarily for service in welded pressure vessels, while AL-6XN is a superaustenitic stainless steel $(24 \% \mathrm{Ni}, 22 \% \mathrm{Cr}, 6.3 \% \mathrm{Mo})$, for pressure vessels and general applications. The main objectives of this work are to quantify the residual stresses introduced in the cladded plates as a result of the explosion welding process and to analyze the impacts of post weld annealing on the microstructure, properties and the residual stress state of the cladded materials.

\section{Experimental Procedure}

Materials. Plates of ASME SA516-70 carbon steel and AL-6XN superaustenitic stainless steel were explosion welded in parallel configuration with the ASME SA516-70 steel being the base plate and the AL-6XN stainless steel being the clad metal or flyer plate. Prior to welding, both steel plates were inspected for surface defects and ground in order to increase contact area and assist the bonding process. The final dimensions of the composite plates were $762 \times 330 \times 31.6 \mathrm{~mm}$. The welding procedures were carried out by Dynamic Materials Corporation (US).

Stress relief heat treatment. Post weld heat treatment for stress relief was carried out in a conventional furnace (with no controlled atmosphere) at $600^{\circ} \mathrm{C}$ for $30 \mathrm{~min}$. After annealing, the samples were removed from the furnace and air-cooled. The temperature was selected in order to minimize microstructure modifications (e. g. grain growth, phase transformations) of both materials.

Microstructure analysis. Samples for microstructure analysis were prepared by mechanical grinding followed by polishing in 6 and $3 \mu \mathrm{m}$ diamond suspensions. Etching of the AL-6XN steel was accomplished by using Aqua Regia (nitro-hydrochloric acid) while a $2 \%$ Nital solution was used for etching the SA516-70 carbon steel. Observation of the microstructure was performed by applying Optical Microscopy (OM) and Scanning Electron Microscopy (SEM). Quantitative chemical composition analysis was carried out by using the Energy-Dispersive X-ray spectroscopy (EDX) technique.

Microhardness measurements. Vickers microhardness measurements were performed over cross sections of the cladded interface with a $100 \mathrm{gf}$ load (HV0.1) and 15 s holding time. In total, three microhardness profiles were measured and the average values were determined. The first hardness measurement of each profile began $0.05 \mathrm{~mm}$ beneath the AL- $6 \mathrm{XN}$ steel surface and subsequent measurements were performed in $0.2 \mathrm{~mm}$ steps.

Residual stress analysis. Residual stress analysis was performed by X-ray Diffraction (XRD) on a $60 \times 60 \times 20 \mathrm{~mm}$ piece which was removed from the original welded joint. A laboratory source operating with Co $\mathrm{K}_{\alpha}$ radiation was used and the $2 \times 2 \mathrm{~mm}$ X-ray beam was focused in the center of the AL-6XN surface. The $\sin ^{2} \psi$ method was applied with equally spaced $\psi$ intervals between 0 and $71.57^{\circ}$. The reflections from the austenite (222) and (311) lattice planes were selected for measurement and residual stress analysis. The elastic constants for each reflection were determined by applying the Hill model and the residual stresses were computed for each lattice plane individually. The final residual stress values were obtained by averaging the reflection specific values. 


\section{Results and Discussion}

Microstructure. The microstructure of the cladded interface in the as welded condition is presented in Fig. 1 and Fig. 2, which focus, respectively, on the AL-6XN and SA516-70 sides of the joint. Observation of Fig. 1 indicates that the AL-6XN base material is formed of large equiaxed austenite grains. At a distance of 50-100 $\mu \mathrm{m}$ from the cladded interface the microstructure changes significantly and grain boundaries become difficult to resolve. This is possibly due to intense plastic deformation close to the interface.

The microstructure of the SA516-70 base

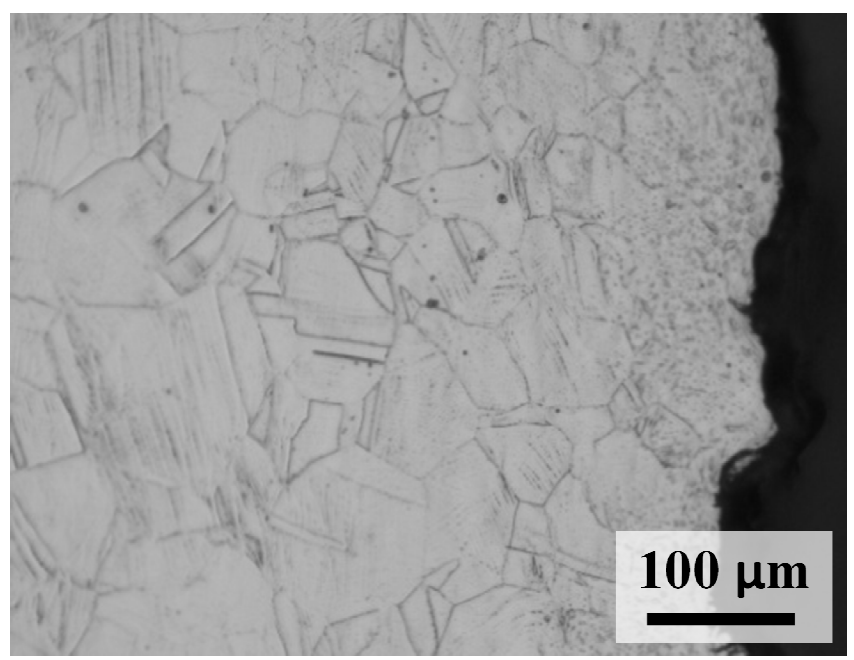

Figure 1: Optical micrograph from the AL-6XN side of the cladded plate.

material consists of fine equiaxed ferrite grains and pearlite colonies, as seen in Fig. 2(a). The cladded interface exhibits the wavy morphology which is typical of explosion cladding. As noticed for the AL-6XN side of the weld, the microstrcutrue also changes significantly as the distance to the interface decreases to approximalty $100 \mu \mathrm{m}$. A detailed view of the SA516-70 microstructure obtained by SEM is presented in Fig. 2(b). Both ferrite and austenite grains (from the SA516-70 and AL-6XN steels, respectively) appear in dark contrast while pearlite appears in bright contrast. From Fig. 2(b) it can be seen that ferrite grains and pearlite colonies appear to become elongated and aligned with the interface. Such features are also indicative of intense plastic deformation occurring at the cladded interface. The microstructure of the cladded interface after heat treatment at $600{ }^{\circ} \mathrm{C}$ for $30 \mathrm{~min}$ is presented in Fig 3 which clearly shows the presence of fine equiaxed grains at the carbon steel side forming a continuous seam along the interface. This is an indication of recrystallization taking place due to the elevated amount of strain energy in the bond region.
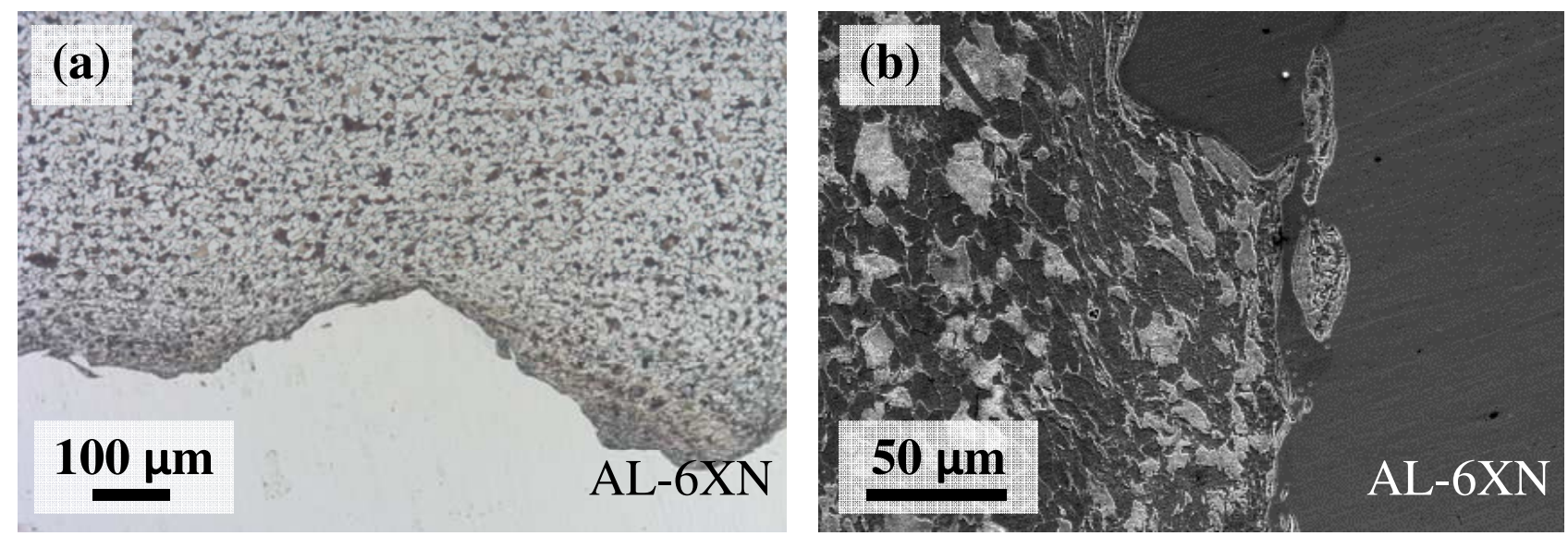

Figure 2: Micrographs from the SA516-70 steel side of the as welded cladded interface (Nital $2 \%$ reagent): (a) overview by OM and (b) detailed view by SEM (pearlite colonies appear in bright contrast).

The variation of chemical composition across the cladded interface was analyzed by SEM coupled with EDX and the results, for the heat treated condition, are presented in Fig. 4. The position of the line scan is indicated by the dotted line and the chemical composition is presented in terms of the concentration of $\mathrm{Fe}, \mathrm{Cr}, \mathrm{Ni}, \mathrm{C}$ and Mo. In the micrograph presented in Fig. 4 a third region is indicated by "A" and "B" labels which possesses a different contrast compared to the SA516-70 and AL-6XN steels, probably due to differences in composition. In the SA516-70 base material EDX reveals negligible amounts of $\mathrm{Ni}, \mathrm{Mo}$ and $\mathrm{Cr}$, and an $\mathrm{Fe}$ concentration of 
approximately $96 \%$. In the intermediate regions, $\mathrm{Fe}, \mathrm{Cr}, \mathrm{Ni}$ and $\mathrm{Mo}$ average concentrations are, respectively, $67,13,15$ and $3 \%$, whereas in the AL-6XN base material the average $\mathrm{Fe}, \mathrm{Cr}, \mathrm{Ni}$ and Mo concentrations are 44, 21, 23 and 8\%. The highlighted particle, therefore, presents an intermediate chemical composition in relation to the base materials. It is likely that this region was formed by melting and mixing near the cladding interface during the explosion welding process. The melted zone is, however, localized and throughout the remainder of the interface a sharp transition is observed between parent materials instead.

Microhardness. Hardness measurements were performed across the cladded interface and the results are presented in Fig. 5, for both as

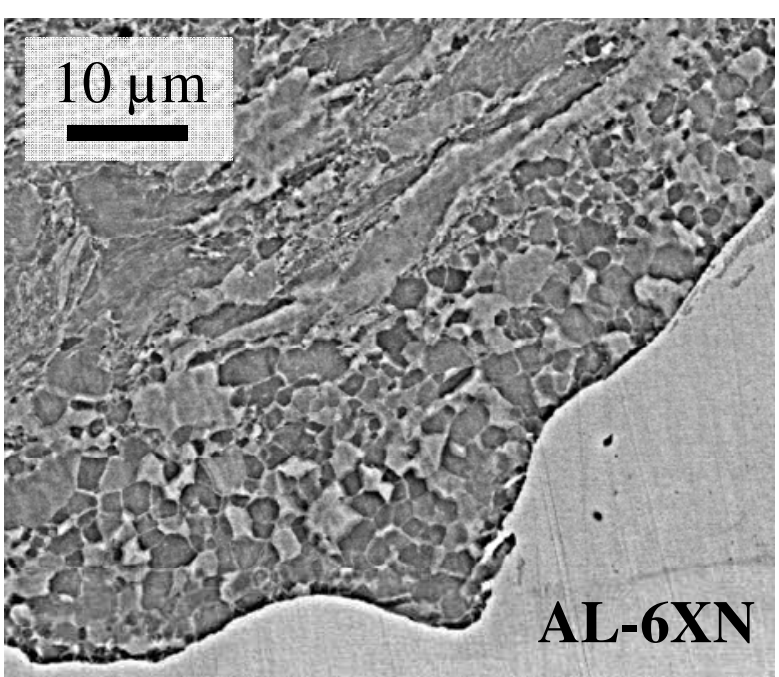

Figure 3: Microstructure of the cladded interface after heat treatment at $600{ }^{\circ} \mathrm{C}$ for 30 $\min$.

welded and heat treated conditions. The hardness values of the base materials prior to the welding process, indicated by the dashed lines, were 196 and 218HV for the SA516-70 and AL-6XN steels, respectively. After welding, the maximum hardness value $(465 \mathrm{HV})$ occurs at the bond interface on the AL-6XN stainless steel side of the joint. The values obtained at the interface are in agreement with other reports on the explosion welding of austenitic stainless steels [16-17]. According to these studies, the observed increase in hardness is due to strain-hardening caused by the plastic deformation at the interface between the two steels. Hardness decreases as the distance from the weld centerline increases and the average hardness values of the AL-6XN and SA516-70 base materials are 270 and $217 \mathrm{HV}$, respectively. After heat treatment, no relevant change in hardness can be observed, probably because the annealing time $(30 \mathrm{~min})$ was too short for significant grain growth processes to take place.
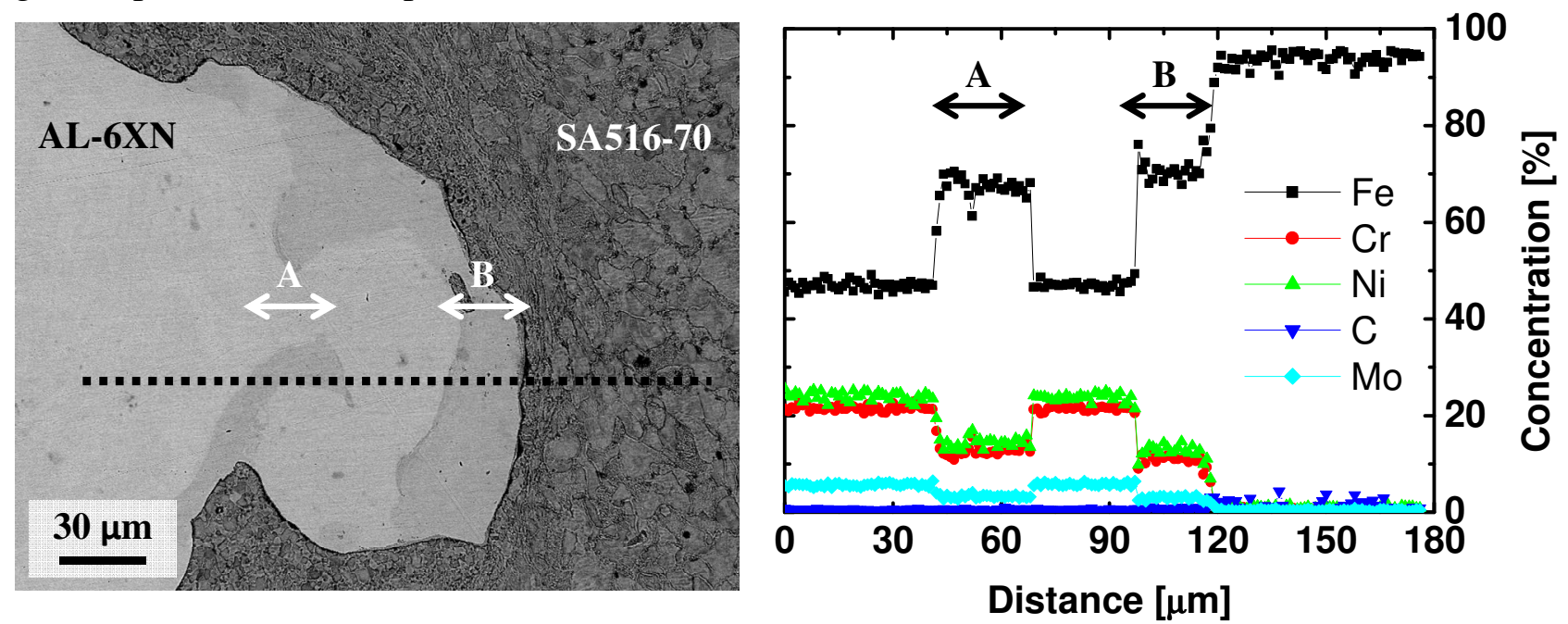

Figure 4: SEM micrograph of the cladded interface after stress relief with variation of chemical composition determined by EDX analyses. 
Residual stress analysis. Residual stress analysis was performed on the AL-6XN side of the welded joints by measuring the distances of the austenite (222) and (311) lattice planes. The results are presented in Fig. 6 in terms of the variation of the average austenite FCC structure lattice parameter "a" with respect to $\sin ^{2} \psi$. In order to better reflect the differences in residual stress values obtained before and after heat treatment, both $\sin ^{2} \psi$ plots are presented in the same graph. The average residual stress calculated from the slope of the linear fit of the $\sin ^{2} \psi$ plots was $700 \pm 30 \mathrm{MPa}$ for the heat treated condition and $93 \pm 10 \mathrm{MPa}$ as indicated in Fig. 6 .

The residual stresses associated with welding of dissimilar materials with similar stiffness are often connected to differences in CTE among the base materials $[7,10]$. The CTE of the individual austenite and ferrite phases is influenced by the presence of dissolved alloying elements and their exact calculation is difficult to perform in the present case. In general, however, CTE of ferrite is smaller than that of austenite [18] so that the SA516-70 steel is supposedly less susceptible to thermal expansion than the AL-6XN steel. Therefore, the residual stresses arise due to CTE mismatch between the AL-6XN (austenitic matrix) and SA516-70 steel (formed of ferrite and pearlite), in addition to the thermal cycles to which welded materials are subject. After heat treatment, significant stress relaxation occurs and the average residual stress value is of $93 \pm 10 \mathrm{MPa}$. This is consistent with the results presented in Fig. 3 , which showed recrystallized grains near the cladded interface after heat treatment. The occurrence of recrystallization near the bond region at the SA516-70 side suggests that diffusion processes might have taken place during the heat treatment within the AL-6XN cladding, thus relieving the residual stresses. Its duration appears, however, to be short to reduce the strain hardening of the cladding (Fig. 5).

\section{Conclusions}

Explosion welding was successfully applied to produce composite sheets of AL-6XN superaustenitic stainless steel and ASME SA516-70 carbon steel. Microstructure analysis revealed the presence of a wavy interface with strong bonding between the two steels, as well as refinement of the grain structure and intense plastic deformation close to the cladded interface. The hardness profile across the welded joint was influenced by strain-hardening taking place during the welding process. Residual stress analysis performed on the AL-6XN side of the composite sheet revealed the presence of tensile stresses of $700 \pm 30 \mathrm{MPa}$. Application of the proposed heat treatment allowed for considerable relaxation of the residual stress level present in the cladded plates to $93 \pm 10 \mathrm{MPa}$. The heat treatment did not, however, decrease hardness in the cladding.

Acknowledgements: The authors thank the funding of the Brazilian national council for scientific and technological development $(\mathrm{CNPq})$. 


\section{References}

[1] R.A. Patterson, Fundamentals of Explosion Welding, in: D. L. Olson, T. A. Siewert, S. Liu, G. R. Edwards (Eds.), ASM Handbook: Volume 6: Welding Brazing and Soldering, ASM International, Ohio, 1993.

[2] A.S. Bahrani, T.J. Black, B. Crossland, The mechanics of wave formation in explosion welding, P. Roy. Soc. Lond. A Mat. 296, 1967, 224-239.

[3] S.A.A. Akbari-Mousavi, L.M. Barrett, S.T.S. Al-Hassani, Explosion welding of metal plates, J. Mater. Process. Tech. 202 (2008) 224-239.

[4] F. Findik, Recent developments in explosion welding, Mater. Design 32 (2011) 1081-1093.

[5] M. Acarer, B. Gülenç, F. Findik, Investigation of explosion welding parameters and their effects on microhardness and shear strength, Mater. Design 24 (2005) 659-664.

[6] A. R. Pyzalla, Internal Stresses in Engineering Materials, in: W. Reimers, A. R. Pyzalla, A. Schreyer, H. Clemens (Eds.), Neutrons and Synchrotron Radiation in Engineering Materials Science, Wiley-VCH., Weinheim, 2008, pp. 21-56.

[7] M.E. Fitzpatrick, M.T. Hutchings, P.J. Withers, Separation of macroscopic, elastic mismatch and thermal expansion misfit stresses in metal matrix composite quenched plates from neutron diffraction measurements, Acta Mater. 45 (1997) 4867-4676.

[8] E. P. Pokataev, Y. P. Trykov, A. S. Kraev, Calculations and experimental determination of residual deflections of bimetallic components produced by explosion welding, Weld. Int. 13 (1999) 482-484.

[9] W. Yasheng, C. Hongneng, M. Ninxu, Measurement of residual stresses in a multi-layer explosion welded joint with successive milling technique, Strain 35 (2008) 7-10.

[10] M. Sedighi, M. Honarpisheh, Experimental study of through-depth residual stress in explosion welded Al-Cu-Al multilayer, Mater. Design 37 (2012) 577-581.

[11] A. Karolczuk, K. Kluger, M. Kowalski, F. Zok, G. Robak, Residual stresses in steel-titanium composite manufactured by explosive welding, Mat. Sci. Forum 726 (2012) 125-132.

[12] Y. Taran, A. M. Balagurov, B. Sabirov, V. Davydov, A. M. Venter, Neutron diffraction investigation of residual stresses induced in niobium-steel bilayer pipe manufactured by explosive welding, Mat. Sci. Forum 768-769 (2014) 697-704.

[13] B. Mateša, D. Kozak, A. Stoić, I. Samardžić, The influence of heat treatment by annealing on clad plates residual stresses, Metalurgjia, 50 (2011) 227-230.

[14]M. Honarpisheh, M. Asemabadi, M. Sedighi, Investigation of annealing treatment on the interfacial properties of explosive-welded Al/Cu/Al multilayer, Mater. Design 37 (2012) 122127.

[15] F. Findik, R. Yilmaz, T. Somyurek, The effects of heat treatment on the microstructure and microhardness of explosive welding, Sci. Res. Essays 6 (2011) 4141-4151.

[16]R. Kaçar, M. Acarer, An investigation on explosion cladding of 316L stainless steel-dinP355GH steel, J. Mater. Process. Tech. 152 (2004) 91-96.

[17] Y. Kaya, N. Kahraman, An investigation into explosion welding/cladding of Grade A ship steel/AISI 316L austenitic stainless steel, Mater. Design 52 (2013) 367-372.

[18]J.W. Elmer, D.L. Olson, D.K. Matlock, The Thermal Expansion Characteristics of Stainless Steel Weld Metal, Weld. Res. Supp. 61 (1982) 293-301. 